\title{
FABRICAÇÃO DIGITAL E GÊNERO: UMA REFLEXÃO SOBRE O ESPAÇO DAS MULHERES NA CONSTRUÇÃO DA REDE DE CONHECIMENTO
}

\author{
Thaciana Belarmino (discente)/UFPE \\ Kátia Araújo (orientador)/UFPE \\ Leticia Teixeira Mendes (co-orientador)/UFPE
}

\begin{abstract}
RESUMO
O artigo propõe uma discussão sobre o papel de protagonismo das mulheres na relação entre design e tecnologias de fabricação digital em dois laboratórios universitários brasileiros. Através da abordagem qualitativa, o material empírico se refere a três entrevistas semi-estruturadas com profissionais de Arquitetura, Urbanismo e Design de gerações diferentes, sendo duas coordenadoras de laboratórios universitários de fabricação digital (sul e nordeste do país) e uma ex-aluna do laboratório do nordeste. Da análise concluímos que as trajetórias profissionais das entrevistadas estão interligadas e apontam o estabelecimento de uma rede de conhecimento sobre o tema e protagonismo feminino na criação e dinâmica desses laboratórios universitários e seus produtos.
\end{abstract}

Palavras-chave: Fabricação Digital; Gênero; Equidade; Universidade; Mulheres.

\section{Introdução}

A sociedade fortemente marcada pela mudança tecnológica é a mesma que vivencia conflitos sociais geradores de desigualdade de classe, raça e gênero. Segundo Gil (2007), a tecnologia e a estruturação social são elementos de um mesmo problema. Como reflexo dos valores sexistas, a discriminação contra os segmentos mais vulneráveis se reflete na sub-representação das mulheres em algumas áreas de conhecimento. Como dados do contexto social mais amplo, destacamos que em 2019 as mulheres representavam apenas 13,6\% dos concluintes em cursos de graduação presencial na área de Computação, Tecnologias da Informação e Comunicação - TIC (MEC - Censo da Educação Superior, 2019), revelando-se forte discriminação e sexismo também neste subcampo tecnológico. Apesar de existirem mulheres exercendo protagonismo de ações visando a modificação deste cenário, observa-se que a sub-representação feminina nessas áreas ainda é premente.

Nesse estudo, vinculado à dissertação de mestrado em andamento, abordamos a participação feminina no contexto universitário, especificamente no campo das tecnologias digitais.

Problematizamos uma amostra relativa às trajetórias de mulheres em carreiras consideradas de prestígio em dois laboratórios acadêmicos de fabricação digital situados, respectivamente, no Sul e no Nordeste do Brasil. O objetivo é projetar discussões sobre a perspectiva de gênero quanto à 
participação e gendramento dos projetos abraçados nesses laboratórios, através da análise de trajetórias de mulheres protagonistas.

Como mencionado por SCHIEBINGER (2001) para os campos das ciências físicas e engenharia, neste trabalho tencionamos questionar se há também resistência à penetração de um pensamento gendrado ou feminista neste viés multidisciplinar do design relacionado às tecnologias de fabricação digital. Londa Schiebinger (2001) aponta que:

A análise de gênero fez mais progressos em alguns campos científicos do que em outros. [...] As ciências físicas e a engenharia, porém, têm resistido mais à análise feminista. Isto pode ser devido ao número extremamente pequeno de pessoas formadas em ambos, física (ou química) e estudos de gênero. Ou seria devido ao fato de que as ciências físicas são, como alega Steven Weinberg, tão impessoais e livres de valores humanos como as regras da aritmética? Estes são os tipos de dilemas que devemos explorar. (SCHIEBINGER, 2001. p.44)

A autora afirma que há tempos os estudos de ciência, tecnologia e gênero vêm apontando a falta de neutralidade da ciência, tanto em relação a gênero, como também etnicidade e outros marcadores (SCHIEBINGER, 2014). Assim, a ideia de buscar o gendramento no próprio pensamento e produto da ciência, para além do tema da participação feminina em contextos laboratoriais, nos parece fundamental para a análise. Por essa ótica, portanto, são pertinentes as reflexões sobre gendramento do design de artefatos digitais, assim como sobre contextos diversos de produção por meio de processos digitais, que será objeto de outros capítulos da dissertação.

A ideia de desenvolver uma análise de gênero sobre trajetórias profissionais de mulheres envolvidas com fazeres científicos e tecnológicos nos parece bem respaldada na perspectiva de Perrot (2007). A autora afirma ser importante dar visibilidade às histórias das mulheres protagonistas e de sucesso em ações relevantes em diferentes tempos históricos, como é o caso das mulheres em carreiras de prestígio aqui abordadas, e não apenas a dimensão do sofrimento envolvido em suas lutas, trazendo visibilidade à participação feminina.

\section{Metodologia}

A metodologia da investigação, que conta com uma pesquisa qualitativa, abordou três pesquisadoras de três diferentes gerações que atuam em dois laboratórios das regiões Sul e Nordeste do Brasil em posições distintas, através de entrevistas realizadas de maneira remota via Google Meet, além de informações coletadas nos sites institucionais. 
As entrevistas foram realizadas de forma semi-estruturada, buscando-se o registro de suas narrativas sobre suas carreiras e outros temas. As questões exploradas se referem à formação acadêmica dessas protagonistas; à conexão entre a carreira e a rede de apoio familiar das entrevistadas; e à estrutura e divisão dos trabalhos dentro dos laboratórios. A partir das reflexões sobre gênero e tecnologia, e considerando as características do universo social tratado - mulheres com formação universitária que estão atuando como protagonistas nesses laboratórios - as análises objetivaram refletir sobre as formas de disseminação do conhecimento relativo às tecnologias de fabricação digital e as formas de participação. As entrevistas também levantaram dados que possibilitam discussão sobre o tipo de projetos privilegiados quanto ao aspecto do gendramento.

\section{Trajetórias das Entrevistadas: dinâmicas de trabalho e aprendizado}

Quanto às três entrevistadas pesquisadas, são elas: a) a entrevistada 1 (nascida na década de 60), professora doutora em Arquitetura e Urbanismo (1986), docente e coordenadora do laboratório A na Universidade X em Santa Catarina/Florianópolis; b) a entrevistada 2 (nascida na década de 70), professora doutora em Design Industrial (1999), docente e coordenadora/colaboradora do laboratório B na Universidade Y em Recife/Pernambuco; c) a entrevistada 3 (nascida na década de 90), arquiteta e urbanista graduada em 2019, ex aluna da Universidade Y e egressa do laboratório B. Nos tópicos a seguir serão apresentados dados e discussões relativas à formação acadêmica e construção do conhecimento; carreira tecnológica e o reduto familiar; e dinâmica dos trabalhos nos laboratórios.

\section{Formação acadêmica e construção do conhecimento em fabricação digital}

A entrevistada 1, protagonista do campo da fabricação digital em uma Universidade do sul do país (Universidade $\mathrm{X}$ ), teve seu contato com as tecnologias de fabricação digital no desenvolvimento do seu doutorado na Faculdade de Engenharia, Arquitetura e Urbanismo da UNICAMP - Universidade Estadual de Campinas (2009). Foi orientada pela professora doutora 4, que obteve formação no MIT Instituto de Tecnologia de Massachusetts, e se consolidou como nome de referência na área, fato que foi mencionado como fator decisivo para sua inserção neste campo profissional e de conhecimento.

Por sua vez, a trajetória da professora 2, que atua no Laboratório B situado em uma universidade pública no Nordeste do Brasil, nos mostra que seu contato com as tecnologias de produção digital se deu, de fato, nas capacitações e workshops para a implementação do citado laboratório B. A professora 2 acredita que, além de sua formação, seu interesse pessoal por máquinas também impulsionaram sua atuação tecnológica. 
Já a entrevistada 3 (arquiteta de formação) faz parte da geração que já teve contato com o tema nas experiências acadêmicas no próprio curso de graduação na universidade $Y$ situada no Nordeste do Brasil, através do qual teve acesso a um programa de intercâmbio no exterior. Ela aponta que descobriu softwares e outras possibilidades de uso para arquitetura no intercâmbio realizado na Austrália. Por outro lado, seu envolvimento com o citado laboratório B (equipamento de uma universidade nordestina), após voltar do intercâmbio, alimentou ainda mais o seu interesse por este campo profissional, através das disciplinas e projetos relacionados ao laboratório ao longo do seu curso.

Assim observamos que a instituição Y (e o laboratório B) teve papel fundamental na trajetória profissional da segunda e da terceira informantes. No caso da terceira, destaca-se ainda que ela parece ter formação maior do que o perfil que seria mais facilmente absorvido no mercado profissional o qual pleiteia - já que, para ela, o mais desafiador não foi obter a formação, mas ser absorvida mais adequadamente pelo mercado de trabalho da região.

Quando perguntado sobre a formação de outras profissionais como produto de seus ensinamentos, a fala de professora 1 chama a atenção pois, além de ter uma série de ex-alunos que se dedicam à carreira acadêmica e outros que estão em processo de ascensão, nota-se o papel importante na formação da Professora 5, doutora em Arquitetura e Urbanismo (2014), que hoje coordena o Laboratório B junto com a entrevistada 2 . A rede acadêmica exemplificada nesses três casos permitiu uma expansão do conhecimento em fabricação digital além dos limites relacionados à ação dessas profissionais, se consideradas isoladamente.

\section{Carreira tecnológica e o reduto familiar}

Em relação ao incentivo e reconhecimento da família, a entrevistada 1 relata que as lembranças de infância no barracão do seu avô, onde havia materiais diferentes e se realizavam atividades como pintura envolvendo diversos membros da família, estão muito presentes em suas memórias. Ela aponta que seu grupo familiar tem "essa vontade de fazer coisas" (ser maker). Seu pai sempre esteve interessado no trabalho que ela desenvolve, e sua casa reflete uma parte de seu trabalho onde se encontra uma variedade de artefatos produzidos em suas atividades.

A entrevistada 2, por seu turno, explica que tem o apoio e reconhecimento da família, principalmente a família núcleo composta de marido e filha, e que isso significa crescer junto com eles. Quando perguntado sobre outro tipo de feedback que recebe de sua família sobre sua atuação profissional, a professora 2 afirma que a geração mais velha entende que ela estudou muito, e que as sobrinhas (geração mais nova) são as que mais têm consciência sobre o trabalho que desenvolve e as 
que mais valorizam essa atuação. É interessante, sobre a narrativa dessa entrevistada em particular, a referência recorrente e elogiosa ao reconhecimento de mulheres da geração mais nova de sua família.

A entrevistada 3, representante da geração mais nova dentre as pesquisadas, trabalha como colaboradora em um escritório de arquitetura. Nessa posição, ela conta que gostaria de trabalhar com tecnologias digitais mais sofisticadas aplicadas à arquitetura; todavia, isso não acontece, já que os escritórios nos quais atua, característicos do mercado de trabalho em arquitetura no NE, utilizam tecnologias mais tradicionais, como AutoCAD, etc., sendo o uso de outras tecnologias digitais, como fabricação digital e modelagem paramétrica, mais escassamente encontradas nesses espaços.

A informante 3 pontua, ainda, o fato de que, a seu ver, a tecnologia aplicada não é facilmente compreendida por pessoas leigas. Por exemplo, ela não consegue explicar seu trabalho de conclusão do curso de arquitetura - que se refere à modelagem paramétrica - para a sua avó, o que seria compreensível pelo dado geracional. Por outro lado, acrescenta que mesmo entre representantes de uma geração mais próxima, como a de seus pais, o propósito do seu trabalho de conclusão também não é facilmente compreendido, sugerindo que a representação das atividades tecnológicas e,sobretudo, as relativas às tecnologias digitais, ainda se apresentam muito abstratas e inacessíveis à compreensão de pessoas leigas.

\section{Dinâmica de trabalho nos laboratórios}

As entrevistadas informaram que os dois laboratórios envolvidos na investigação privilegiam, de maneira exclusiva, projetos associados às atividades acadêmicas desenvolvidas nos cursos das respectivas universidades. No laboratório B (situado no Nordeste), os projetos e ferramentas tecnológicas usadas são definidas pelo grupo e estão ligadas aos interesses das mencionadas disciplinas. Quanto às atividades de pesquisa, os projetos estão vinculados sempre a interesses da universidade e a objetivos sociais, não se privilegiando interesses de organizações privadas. Quanto ao laboratório A (situado no Sul), todos os projetos também precisam estar protocolados com alguma atividade da universidade. Dessa forma, observamos que os recursos e ferramentas privilegiadas também são abordados atendendo aos interesses acadêmicos e projetos correlatos.

Aqui exploramos também a divisão das atividades nos laboratórios pesquisados, que se definem como coordenação, atividades de professores pesquisadores e atividades de monitores. Quanto à atividade gestora, a entrevistada 1 coordena o laboratório A, que tem foco voltado para design de produto, desde sua implantação na Universidade X (sul do país), há oito anos. Na dinâmica das atividades, os monitores que participam do laboratório têm uma quantidade de horas de trabalho a 
cumprir e vão atendendo alunos e pesquisadores em horas previamente marcadas, auxiliando e manipulando o maquinário. Os produtos escolhidos para abordagem obedecem à ordem de chegada sistematizada no aplicativo Trello. A entrevistada 1 registrou que sente falta de recursos para viabilizar a manutenção das máquinas e para ofertar mais bolsas de monitoria.

O laboratório B (Nordeste do Brasil), coordenado pela entrevistada 2, é voltado para a produção de modelos, maquetes e mock-ups, onde os alunos podem criar seus protótipos de projetos acadêmicos. Refletindo sobre o possível gendramento quanto à divisão sexual do trabalho neste laboratório, a entrevistada 2, que atua desde a fundação em 2016, afirma que a divisão de trabalhos no espaço é equitativa em termos de gênero. Igualmente, as afirmações da informante sugerem que as dinâmicas entre os diferentes níveis hierárquicos de participantes também é movida pelo valor educacional. A exemplo disso, a escolha dos projetos e produtos a serem efetivamente elaborados é definida tendo como critério o atendimento das disciplinas, à pesquisa e à extensão vinculados à universidade. Os próprios alunos podem manipular as máquinas de acordo com os projetos realizados, normalmente atrelados a algum professor.

A entrevistada 2 relata que, durante a pandemia do COVID-19 o laboratório voltou seus esforços para a produção de equipamentos de proteção individual - EPI's utilizando as máquinas de fabricação digital, tendo confeccionado mais de vinte mil hastes para os escudos faciais (Imagens 1 e 2). Com esta decisão, o laboratório B saiu de uma rotina de estudo e experimento para uma rotina de fabricação efetiva, atuando durante certo tempo como uma unidade fabril.

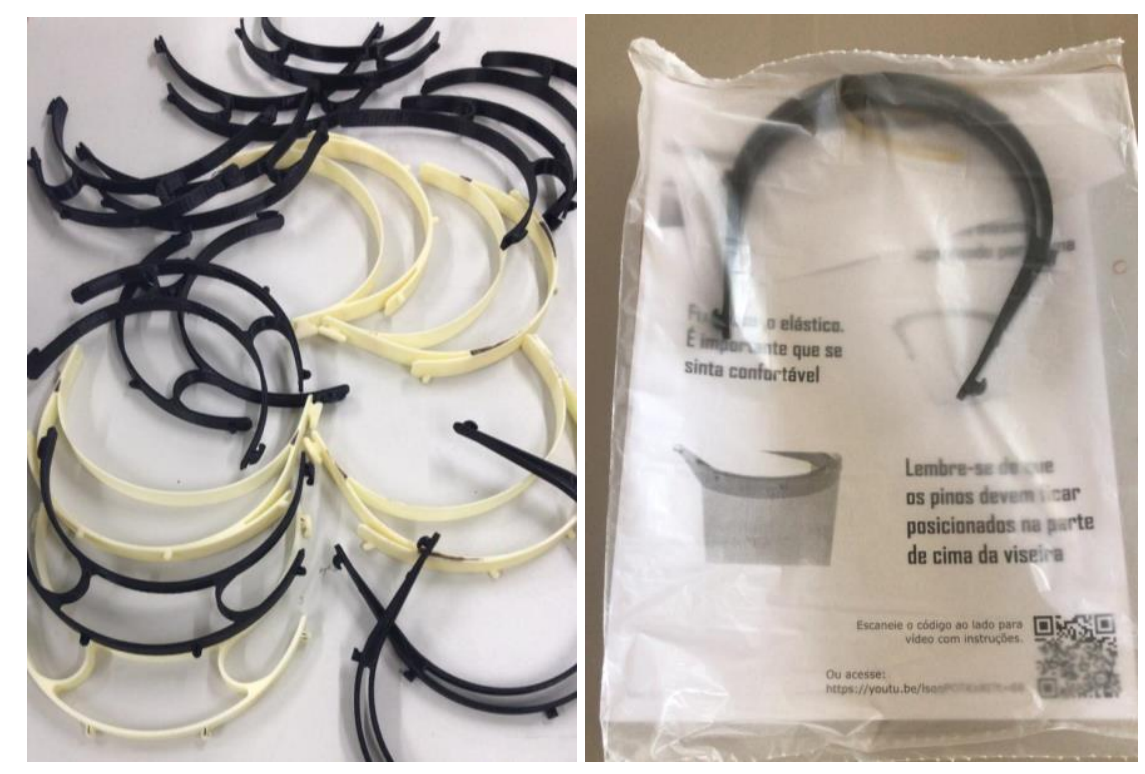

Figura 1 e 2. Hastes para máscara de proteção facial do tipo Face Shield desenvolvida através de impressão 3D pelo Laboratório B/Universidade Y. Fonte: adufepe.org.br. 
É válido destacar o aspecto gendrado desta decisão, já que mesmo contrariando possíveis pressupostos técnicos acadêmicos sobre o uso do equipamento (ensino e pesquisa), o laboratório voltou-se a uma produção extensionista de certa escala. Essa adaptação temporária foi executada para atender à demanda social do combate à crise sanitária, pela dedicação à produção massiva de um artefato fundamental à proteção individual no combate à pandemia do COVID-19, entretanto indisponível no mercado de consumo à época.

\section{Conclusão}

Da análise das falas das entrevistadas, observamos que as trajetórias profissionais das três mulheres pesquisadas, que exercem todas efetivo protagonismo na área, estão inter-relacionadas, apesar dos caminhos próprios que as levaram a atuar nos laboratórios de fabricação digital. A sororidade e inclusão de mulheres através do conhecimento no contexto desses laboratórios cria também um ambiente de representatividade que inspira outras jovens a enxergar a possibilidade de exercício dessa carreira tecnológica. As protagonistas dos laboratórios entrevistadas - seja a pesquisadora sênior, seja a pesquisadora cujo ingresso na área é mais recente, seja ainda a profissional arquiteta recém-formada - todas têm certa consciência de seu papel enquanto disseminadores de novas tecnologias e catalisadoras de oportunidades de formação profissional e ascensão social para outras mulheres em formação.

Observa-se também que a criação dos próprios laboratórios acadêmicos aqui tratados tiveram forte empenho de mulheres em suas fundações. É válido destacar que esses laboratórios vêm contribuindo significativamente para a formação de outras mulheres no campo das tecnologias de fabricação digital e, consequentemente, vem colaborando com a inclusão feminina nesta área de conhecimento, apesar de não possuírem políticas específicas para a inclusão feminina. Assim, compreendemos que suas ações representam algo que está ao nível das consciências individuais das mulheres protagonistas envolvidas. De todo modo, os projetos e produtos resultantes, bem como as divisões de trabalho no laboratório, apresentam um claro compromisso com os propósitos de equidade de gênero.

Por fim, pontuamos que o tema do gendramento na escolha dos projetos privilegiados, processo já observado no exemplo descrito da produção das face shields, será abordado mais densamente em análises futuras para a dissertação de mestrado. Sobre esse tema, já se pode adiantar também as ideias teóricas de Londa Schiebinger (2014) sobre princípios privilegiados em análises de projetos e produtos que contemplem as dimensões de sexo e gênero. 


\section{Agradecimentos}

À Coordenação de Aperfeiçoamento de Pessoal de Nível Superior (CAPES) pelo recurso de bolsa à mestranda pesquisadora. Às profissionais entrevistadas que agregaram à pesquisa com suas histórias de vida e relatos que inspiram muitas outras mulheres.

\section{Referências}

GIL, E. P. Technofeminism de Judy Wajcman [reseña en línea]. 2007. UOC Papers. N. 5. Disponível em: http://www.uoc.edu/uocpapers/5/dt/esp/gil.pdf. Acesso em: 20 mai. 2021.

MEC. Instituto Nacional de Estudos e Pesquisas Educacionais (Inep). Censo da Educação Superior 2019. Brasília: Inep, 2019.2 Disponível em: https://download.inep.gov.br/educacao superior/censo superior/documentos/2020/Apresentacao Censo da Educacao Superior 2019.pdf. Acesso em: 25 mai. 2021.

PERROT, M. Minha História das Mulheres. Tradução de Ângela M. S. Corrêa. São Paulo: Contexto, 2007.

SCHIEBINGER, Londa. O feminismo mudou a ciência? Bauru-SP, EDUSC, 2001 [original em inglês: Has feminism changed science? Cambridge, Harvard University Press, 1999].

SCHIEBINGER, Londa. Expandindo o kit de ferramentas agnotológicas: Métodos de Análise de Sexo e Gênero. In: Revista Feminismos, v. 2, n. 3, 2014. 